\title{
A COMPARTIMENTAÇÃO DO RELEVO COMO SUBSÍDIO AOS ESTUDOS AMBIENTAIS NO MUNICÍPIO DE ITUIUTABA-MG
}

\section{The compartmentation of relief as subsidy to environmental studies in the municipality of Ituiutaba-MG}

\author{
Fernanda Pereira Martins \\ Universidade Federal de Minas Gerais, Belo Horizonte, Minas Gerais, Brasil \\ martinsgeo@hotmail.com.br
}

Rildo Aparecido Costa

UFU, Ituiutaba, Minas Gerais, Brasil

rildocosta1@yahoo.com.br

Artigo recebido em 22/02/2013 e aceito para publicação em 20/04/2014

RESUMO: O município de Ituiutaba está localizado na mesorregião geográfica do Triângulo Mineiro e Alto Paranaíba. Possui área municipal de $2.598,046 \mathrm{~km}^{2}$ e perímetro urbano correspondente a $37,40 \mathrm{~km}^{2}$. A falta de dados sobre as características ambientais e tipo de ocupação da terra é um impedimento à elaboração de planejamentos ambientais no município. Nesta ótica, objetivou-se efetuar a compartimentação morfológica de Ituiutaba seguindo a taxonomia proposta por Ross (1992), contemplando do $1^{\circ}$ ao $4^{\circ}$ táxon. E a análise das características ambientais do município foi elaborada seguindo a metodologia de Ab’Sáber (1969) referente à Compartimentação Morfológica, Estrutura Superficial e Fisiologia da Paisagem. A compartimentação foi elaborada a partir do estudo de bibliografias sobre a área de estudo e análise da dinâmica do relevo pretérito e atual. Os materiais utilizados foram imagens de satélite TM/Landsat5, fotografias aéreas e as cartas topográficas. Assim, quatro grandes unidades foram mapeadas para $4^{\circ}$ táxon, sendo elas: o Planalto de Ituiutaba, as Superfícies de Cimeira, Chapada Embutida e Depressão Interplanáltica. As classes de solo encontradas na área são: Latossolo vermelho; Gleissolo Melânico; Neossolos Litólicos; Argissolo Vermelho-Amarelo e Nitossolo Vermelho. Enquanto que Agricultura; Pastagem; Vegetação Natural; Corpos d'água e Malha Urbana são as categorias de uso da terra encontradas. Este trabalho fornecerá dados para o futuro estudo de vulnerabilidade ambiental do município de Ituiutaba. Palavras-chaves: compartimentação morfológica; caracterização ambiental; município de Ituiutaba.

ABSTRACT: The municipality of Ituiutaba is located in the state of Minas Gerais, specifically in the geographical mesoregion of Triângulo Mineiro e Alto Paranaíba. It has an municipal area of 2.598,046 km² and an urban perimeter of $37,40 \mathrm{~km}^{2}$. The lack of data about the environmental characteristics and kind of land occupation are an obstacle to the preparation of environmental plans in the municipality. In this sense, the objective was to make a morphologic compartimentation of Ituiutaba following the taxonomy proposed by Ross (1992), comprising the $1^{\text {st }}$ to $4^{\text {th }}$ taxon. And the analysis of the environmental characteristics of the municipality was made following the methodology of Ab'Sáber (1969) on the Morphology Compartimentation, Superficial Structure and Landscape Physiology. The compartment was made from the research using the bibliography about the study area and the analysis of the past and current landform dynamic. The materials used were TM/Landsat 5 satellite images, aerial photographs and topographic maps. Thus, four major units have been mapped, being: Planalto de Ituiutaba, Superfícies de Cimeira, 
Chapada Embutida e Depressão Interplanáltica. The soil classes that were found are: red Oxisol; red-yellow Ultisol; Melanic Gleysol; Lithic Orthents and red Afisols. Whereas agriculture; pasture; natural vegetation; water bodies and urban area are the categories of land use found. This work will give data to a future study of environment vulnerability of Ituiutaba's municipality.

Keywords: morphologic compartmentation; environmental characterization; municipality of Ituiutaba.

\section{INTRODUÇÃO}

O relevo é resultado da ação de processos morfogenéticos, incluindo fatores exógenos e endógenos, e sua atuação resulta na formação de diversificados ambientes naturais. Neste panorama o homem, como ser social, interfere no relevo e cria situações ao construir e reordenar os espaços físicos. Todas as modificações inseridas pelo homem no meio natural alteram o equilíbrio da natureza que não é estática, mas que apresenta quase sempre um dinamismo harmonioso em evolução contínua, quando não afetada pelo homem ou catástrofes naturais (ROSS, 1991). Assim, o homem atua modificando o relevo e promovendo alterações na referida evolução (CASSETI, 1995).

Isto ocorre porque é imperativo ao homem como ser social expandir-se, tanto demograficamente como técnica e economicamente, tornando-se evidente que apareçam nesse processo os efeitos contrários (ROSS, 1991). Toda ação humana no ambiente natural ou alterado causa algum impacto em diferentes níveis, gerando alterações com graus diversos de agressão, podendo alcançar processos muitas vezes irreversíveis.

Por isso, estas ações devem ser subsidiadas em uma minuciosa compreensão do ambiente e das leis que o regem. E com intuito de prevenir, muito mais do que corrigir, faz-se necessária a elaboração de diagnósticos ambientais, para que se possa elaborar prognósticos, e com isso estabelecer diretrizes de uso dos recursos naturais de maneira otimizada, minimizando a deterioração da qualidade ambiental (ROSS, 1991).

Nesta ótica é imprescindível que o planejamento ambiental esteja embasado tanto em estudos prévios sobre as características naturais, quanto em estudos da dinâmica ocupacional do mesmo, afim de que o homem possa realizar suas atividades com o mínimo de impacto sobre os recursos naturais e sobre a dinâmica natural do espaço.
A partir do exposto, objetiva-se compartimentar o relevo do município de Ituiutaba seguindo a taxonomia propostas por Ross (1991) e gerar dados que contemplem os níveis metodológicos propostos por Ab'Sáber de Compartimentação Morfológica, Estrutura Superficial e Fisiologia da Paisagem para uma caracterização ambiental integrada. Além de gerar dados para subsidiar a futura elaboração do mapa de vulnerabilidade ambiental do município.

\section{A ÁREA DE ESTUDO}

\section{Caracterização geográfico-geomorfológica do mu- nicípio de Ituiutaba-MG}

O município de Ituiutaba está localizado na mesorregião do Triângulo Mineiro e Alto Paranaíba, especificamente na microrregião de Ituiutaba, estado de Minas Gerais (Figura1). Sua área é constituída por duas grandes bacias hidrográficas que abrangem cerca de $95,18 \%$ da área total, sendo elas, a bacia hidrográfica do rio Tijuco e a bacia hidrográfica do rio da Prata.

A área de estudo se encontra aproximadamente a $137 \mathrm{~km}$ de Uberlândia e a $673 \mathrm{~km}$ da capital do estado, Belo Horizonte.

Ao caracterizar o relevo regional, Del Grossi (1991) utilizou a denominação proposta por Ab’Sáber (1971) de "Domínios dos Chapadões Tropicais do Brasil Central", constituindo a sub-unidade Planalto Setentrional da Bacia Sedimentar do Paraná. Esta caracterização física indica que o relevo regional é resultado da evolução da Bacia do Paraná, mostrando-se relativamente homogêneo, cuja morfologia encontra-se caracterizada por chapadas.

Baccaro (1991) afirmou que as formas desse relevo vêm sendo trabalhadas desde o período Terciário (o termo "Terciário" não integra mais o Quadro Estratigráfico Internacional da Comissão Internacional sobre Estratigrafia, sendo substituído e apontado atualmente pela literatura como Paleógeno). 
No decorrer desses períodos, através de alterações climáticas e implicações tectônicas, o relevo regional sofreu extenso processo de pediplanação, laterização e dissecação, evidenciada por King (1962) e Barbosa (1970), resultando nas formas atuais.

Essas superfícies antigas, cujos testemunhos são encontrados na paisagem atual e que evidenciam uma superfície de erosão, são, provavelmente, resultado do aplainamento Sul-Americano que terminou no Terciário superior (provavelmente Oligoceno-Mioceno). Esses altos aplainados são assoalhados por lateritas que formam uma capa contínua em alguns locais e constituem concreções no solo. Muitas vezes essas capas resistentes são responsáveis pela preservação dos testemunhos da superfície (DEL GROSSI, 1991).

Martins e Rocha (2011) detectaram a partir de trabalhos de campo e em estudos de gabinete com análise de cartas topográficas e mapas hipsométricos, que os relevos residuais na área de estudo se encon- tram entre as cotas altimétricas de 600 e $750 \mathrm{~m}$ nos interflúvios das principais bacias.

Essas feições possuem um arcabouço formado basicamente de quartzos de matriz areno-argilosa e conglomeráticos, cimentados por carbonato e sílica. Sua formação é condicionada a partir da atuação da rede de drenagem, a qual promove a retração das escarpas e a remobilização dos materiais ao longo das vertentes, que por processos de coluvionamento posterior recobre as cascalheiras formando as linhas de pedra (SILVA et al, 2010).

Quanto ao clima, Köppen o classificou como Aw, megatérmico: tropical com verão chuvoso (Outubro a Abril) e inverno seco (Maio a Setembro). As temperaturas oscilam entre $14^{\circ} \mathrm{C}$, comum no mês de Junho, a $31^{\circ} \mathrm{C}$ em Dezembro. Ituiutaba possui um dos maiores acúmulos pluviométricos da região, tendo variado de 10.800 a $10.000 \mathrm{~mm}$ o índice de chuvas acumuladas para sete anos, no recorte temporal de 2002 a 2008 (PRADO; SOUSA, 2010).

Figura1. Área de estudo.

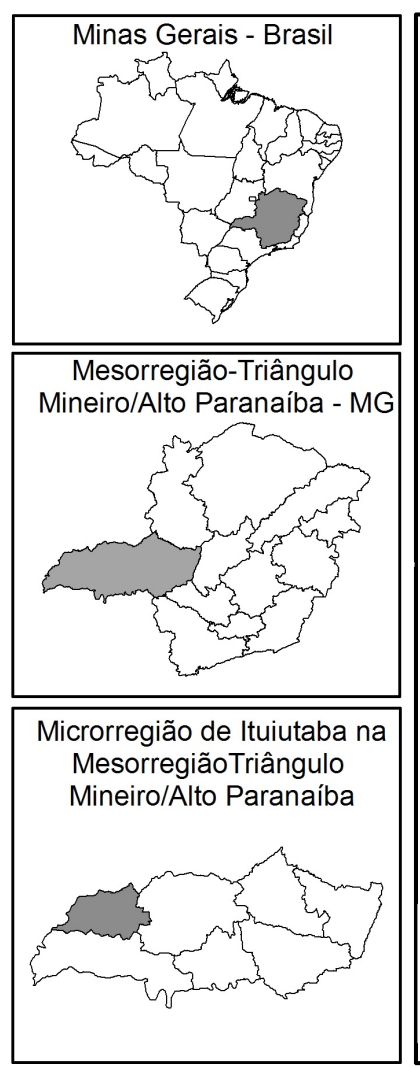

\section{Localização do Município de Ituiutaba na Microrregião de Ituiutaba/MG}

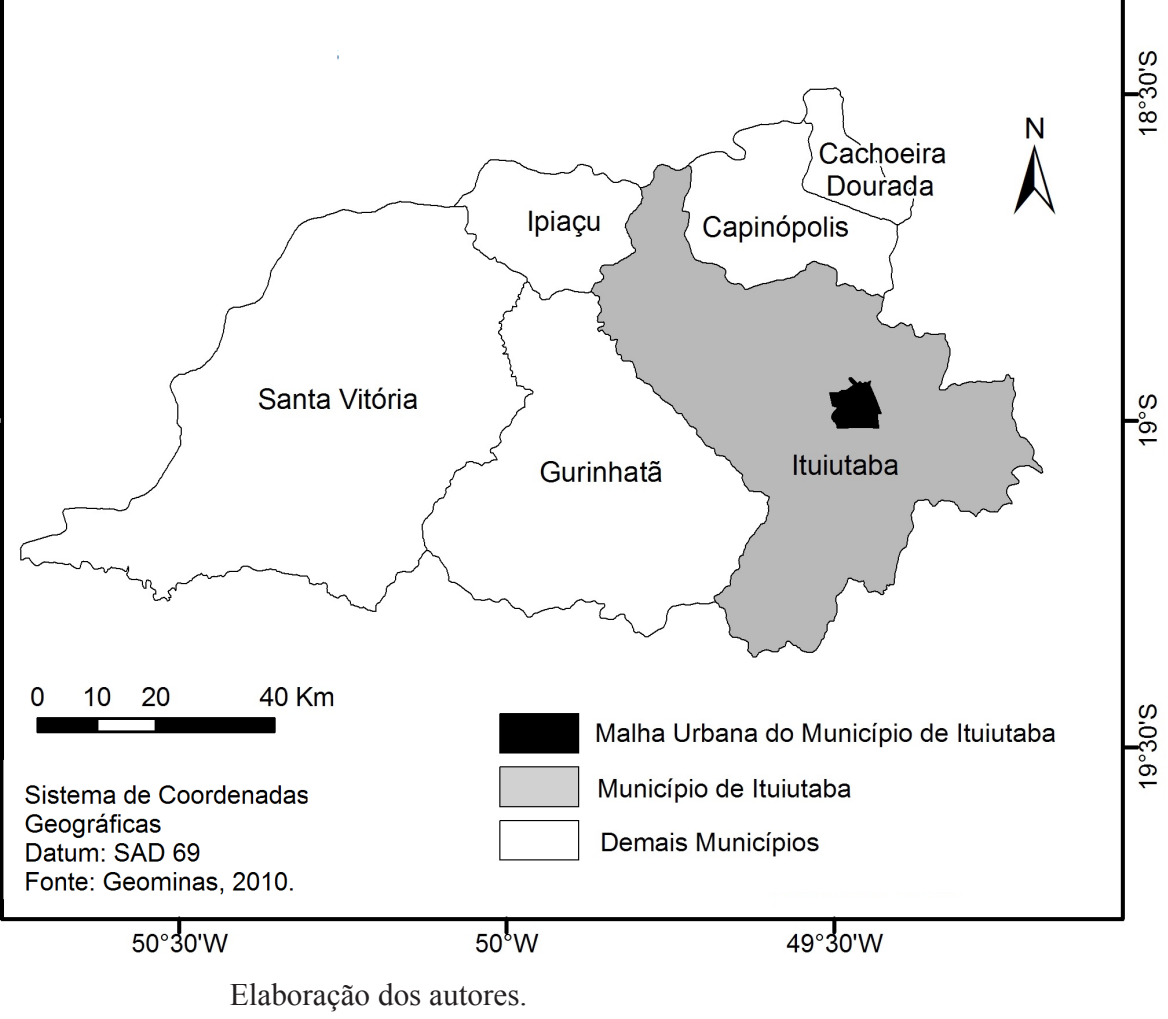

Soc. \& Nat., Uberlândia, 26 (2): 317-331, mai/ago/2014 
Para elaboração da compartimentação morfológica, recorreu-se à metodologia taxonômica do relevo proposta por Ross (1992), a partir da qual, foram definidos os parâmetros morfométricos.

Para a composição das características do georelevo de cada compartimento em específico, utilizou-se os pressupostos metodológicos desenvolvidos por Ab'Sáber (1969), a partir dos quais foram sistematizadas as informações concernentes à compartimentação morfológica, estrutura superficial e fisiologia da paisagem.

\section{COMPARTIMENTAÇÃO MORFOLÓGICA}

A compartimentação morfológica foi estabelecida a partir de dados obtidos de imagens de satélite, fotografias aéreas e cartas topográficas, dando ênfase maior ao grau de dissecação do relevo, comandada pela distância dos interflúvios e o aprofundamento da drenagem (CREPANI et al., 1998) e, principalmente, pela caracterização processual que pode ser evidenciada através das formas de agradação e degradação identificadas.

O mapeamento da compartimentação morfológica do município de Ituiutaba foi elaborado no software ArcGis 9.2.

\section{Obtenção de dados morfométricos}

Para lograr a quantificação dos parâmetros morfométricos, elaborou-se mosaico das Cartas topográficas de Cachoeira Dourada, Gurinhatã, Ituiutaba e Serra de São Lourenço na escala de 1:100 000.

Os índices de morfometria do primeiro nível metodológico foram estabelecidos manualmente, contemplando as seguintes variáveis: Dimensão dos Interflúvios; Aprofundamento do Talvegue; Declividade dos Fundos de Vale; Declividade Média dos Interflúvios; Densidade Hidrográfica.

\section{ESTRUTURASUPERFICIAL: MAPADE SOLOS DO MUNICÍPIO DE ITUIUTABA}

A caracterização da Estrutura Superficial do município de Ituiutaba foi feita a partir de classificação pedológica. Para tanto, fez-se aquisição da base de dados de cobertura superficial do estado de Minas Gerais disponível no site GEOMINAS, o qual foi recortado dentro do limite municipal de Ituiutaba.

A nomenclatura das classes de solos foi renomeada utilizando o sistema brasileiro de classificação de solos da Embrapa (2006).

Prosseguiu-se com o cálculo da representatividade das classes de solo encontradas em cada compartimento estudado.

\section{FISIOLOGIA DA PAISAGEM: MAPEAMENTO DO USO E OCUPAÇÃO DA TERRA}

Para o mapeamento do uso e ocupação da terra no município de Ituiutaba-MG, utilizou-se a imagem de satélite TM/Landsat 5, órbitas 221 e 222, ponto 73 de Agosto de 2011. Nesta etapa foram utilizados os Sistemas de Informação Geográfica ArcGis 9.2 e Envi 4.2.

No software Envi 4.2 foi feito o mosaico das órbitas/ponto 221/73 e 222/73 e, posteriormente, fez-se a composição colorida R4G5B3. O registro da imagem foi feito tendo como parâmetro as imagens do mapeamento das áreas de cerrado brasileiro do Ministério do Meio Ambiente.

No ArcGis 9.2 fez-se o mapeamento das classes de uso e ocupação da terra pelo método de classificação supervisonada que, de acordo com Rosa (2007), corresponde à interpretação de imagens de sensoriamento remoto auxiliada por computador.

As classes de uso da terra estabelecidas para a área de estudo foram: Área Urbana, Agricultura (a qual inclui a cana-de-açúcar e culturas anuais como soja, milho, sorgo, etc), Pastagem, e Vegetação Natural. Devido à sua pequena extensão, as áreas de reflorestamento foram consideradas na classe de vegetação natural.

A chave de interpretação da composição colorida em estudo (R4G5B3) foi baseada em Rudorff et al. (2010) e a partir de interpretação visual e trabalhos de campo realizados nos dias 26/08/2011 e 28/08/2011 para aquisição de coordenadas com o auxílio de receptor GPS (Global Positioning System) e fotografias para confrontar com os dados de gabinete.

Em sequência, calculou-se a área de cada categoria do uso da terra na totalidade do município de Ituiutaba, e, posteriormente, qual sua representatividade dentro de cada compartimento morfológico em específico. 


\section{RESULTADOS E DISCUSSÃO}

\section{Compartimentação morfológica do município de Ituiutaba}

Ao analisar a dinâmica dos processos de agradação e degradação no "Pontal do Triângulo Mineiro", Martins e Rocha (2011) observaram que as porções leste e nordeste são as mais elevadas, e que os rios Tijuco, São Lourenço e Prata correspondem aos principais pontos de dissecação na Bacia do Rio Paranaíba (Figura 2). Esses rios estão presentes no município de Ituiutaba e correspondem às drenagens de maior importância, tanto por serem agentes ativos na esculturação do relevo, quanto socialmente, na captação de água (Rio Tijuco e Ribeirão São Lourenço).

Figura 2 - Hipsometria do Município de Ituiutaba - MG
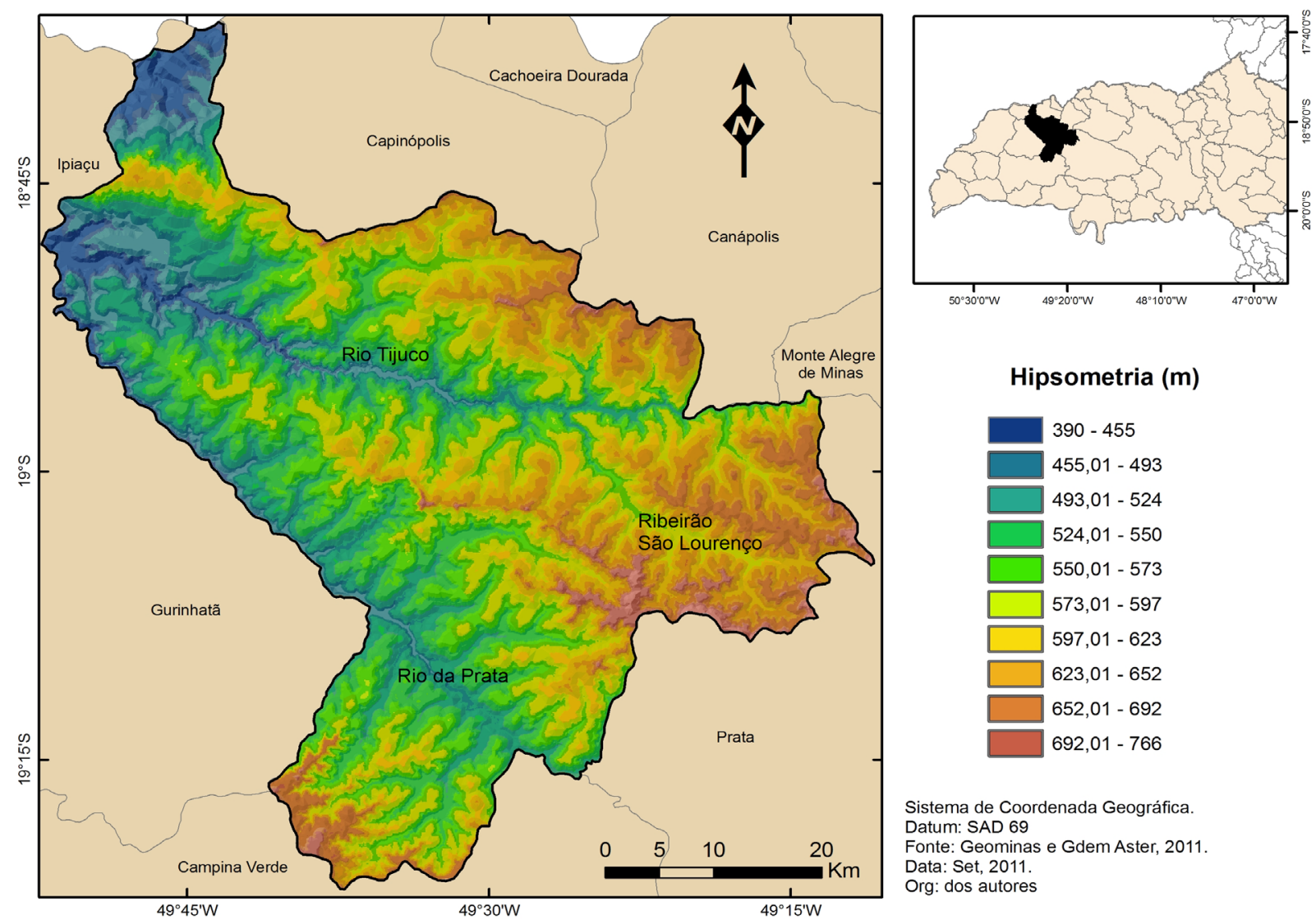

Hipsometria (m)

$390-455$

$455,01-493$

$493,01-524$

$524,01-550$

$550,01-573$

$573,01-597$

$597,01-623$

$623,01-652$

$652,01-692$

$692,01-766$

Sistema de Coordenada Geográfica.

Datum: SAD 69

Fonte: Geominas e Gdem Aster, 2011.

Data: Set, 2011.

Org: dos autores

Fonte: Geominas e Gdem aster, 2011. Adaptação dos autores. 
Nos interflúvios dos rios Tijuco e Prata, nas margens direita e esquerda, a atuação da drenagem deixou apenas os relevos residuais (Figura 3). Entretanto, a drenagem ainda continua a entalhar essa feição geomorfológica, erodindo suas bordas.
A grande dissecação de oeste para leste a partir dos tributários do rio Paranaíba mostram que as áreas com a presença de relevos residuais estão preservadas apenas nos divisores, ou seja, sua concentração está no centro (MARTINS; ROCHA, 2011).

Figura 3. Relevos residuais no município de Ituiutaba-MG.

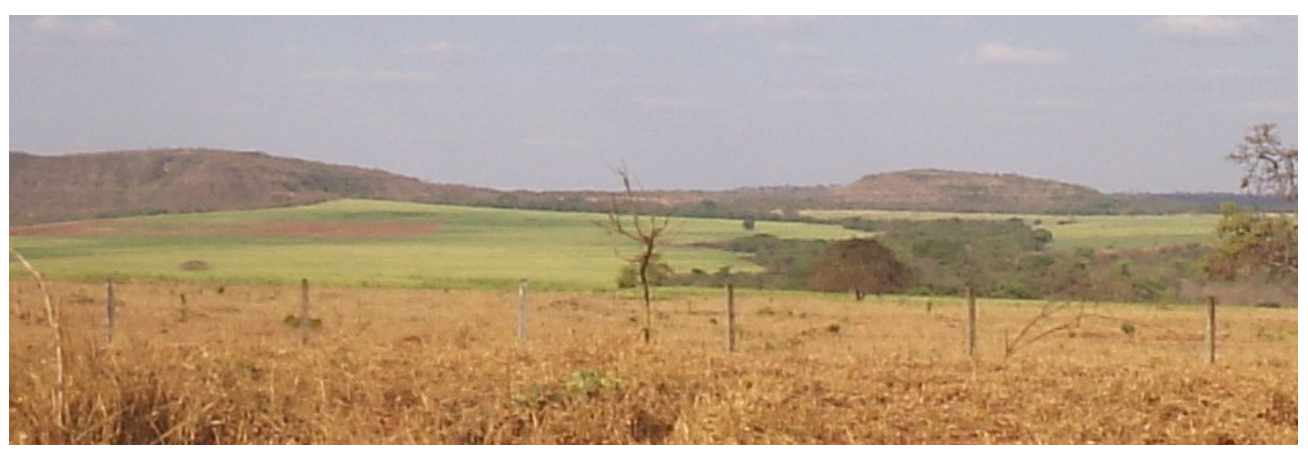

Foto dos autores, 2011.

Nessa perspectiva, Ituiutaba, conforme Mamede et al. (1983), está inserida na unidade Planaltos e Chapadas da Bacia Sedimentar do Paraná, ( $\left(1^{\circ}\right.$ táxon (ROSS, 1992)), constituindo a sub-unidade Planalto Setentrional da Bacia Sedimentar do Paraná ( $2^{\circ}$ táxon (Ross, 1992)), caracterizada por litologias de espessuras e resistências distintas (Quadro 1).
Constatou-se que este arranjo estrutural, submetido às ações, principalmente da rede de drenagem, promove a formação de quatro Unidades Morfológicas ( $3^{\circ}$ táxon (ROSS, 1992)), sendo eles o Planalto de Ituiutaba, as Superfícies de Cimeira, Chapada Embutida e Depressão Interplanáltica e suas respectivas subunidades (4º́xon (ROSS, 1992)).

Quadro 1. Compartimentação morfológica e dados morfométricos do município de Ituiutaba-MG.

\begin{tabular}{|c|c|c|c|c|}
\hline $\begin{array}{l}\text { Unidade Morfoes- } \\
\text { trutural }\end{array}$ & $\begin{array}{l}\text { Unidade Morfoes- } \\
\text { cultural }\end{array}$ & \multicolumn{2}{|r|}{ Unidade Morfológica } & Sub-Unidade Morfológica \\
\hline $1^{\circ}$ Taxon & $2^{\circ}$ Taxon & & $3^{\circ}$ Taxon & $4^{0}$ Taxon \\
\hline \multirow{6}{*}{ 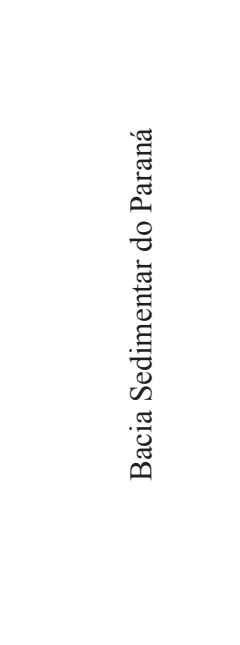 } & \multirow{6}{*}{ 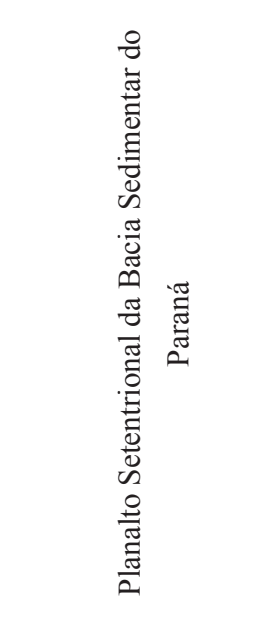 } & \multirow{2}{*}{ I } & \multirow{2}{*}{ Planalto de Ituiutaba } & $\begin{array}{c}\text { (Ia) Planalto - Margem Direita do } \\
\text { Tijuco }\end{array}$ \\
\hline & & & & $\begin{array}{c}\text { (Ib) Planalto - Margem Esquerda do } \\
\text { Tijuco }\end{array}$ \\
\hline & & \multirow{2}{*}{ II } & \multirow{2}{*}{ Superfícies de Cimeira } & $\begin{array}{l}\text { (IIa) Superfície de Cimeira do Ribei- } \\
\text { rão São Lourenço }\end{array}$ \\
\hline & & & & $\begin{array}{c}\text { (IIb) Superfície de Cimeira do Ribei- } \\
\text { rão São Gabriel }\end{array}$ \\
\hline & & III & Chapadas Embutidas & $\begin{array}{c}\text { (III) Chapada Embutida do Alto São } \\
\text { Lourenço }\end{array}$ \\
\hline & & IV & Depressão Interplanáltica & $\begin{array}{c}\text { (IV) Depressão Interplanáltica do } \\
\text { Tijuco }\end{array}$ \\
\hline
\end{tabular}

Organização dos autores. 
A compartimentação taxonômica de Ross, do $1^{\circ}$ ao $4^{\circ}$ Táxon, pode ser visualizada no Quadro 1.

Conforme Guerra e Guerra (1997), os planaltos constituem um termo de valor apenas descritivo se não for associado ao problema da estrutura. Sendo utilizado para definir uma superfície elevada, mais ou menos plana delimitada por escarpas íngremes onde o processo de degradação supera os de agradação. Esta é a forma de relevo tabular, extensa, que ao menos por um dos dois lados é circundada por superfícies mais baixas. Já as superfícies de cimeira representam as áreas de maiores altitudes, onde ocorre a presença marcante de relevos residuais.

As chapadas são do ponto de vista geomorfológico um planalto sedimentar típico, pois trata-se de um acamamento estratificado que, em certos pontos, está nas mesmas cotas da superfície de erosão, enta- lhadas em rochas pré-cambrianas. Enquanto que as depressões são representadas pelas áreas dissecadas, embutidas nos planaltos, cujas feições morfológicas estão relacionadas à litologia, representadas por basalto (GUERRA; GUERRA, 1997).

\section{Análise Morfométrica dos Compartimentos do Re- levo do Município de Ituiutaba/MG}

Os compartimentos referentes à $4^{\circ}$ Taxonomia do relevo estão espacializados na Figura 4.

Planalto de Ituiutaba - Nessa unidade $\left(3^{\circ}\right.$ táxon (ROSS, 1992)), considerando os aspectos de dissecação do relevo, foram definidas as seguintes subunidades: Planalto - Margem direita do rio Tijuco e Planalto - Margem esquerda do rio Tijuco ( $4^{\circ}$ táxon) (ROSS, 1992).

Figura 4. Compartimentação Morfológica do Município de Ituiutaba - MG
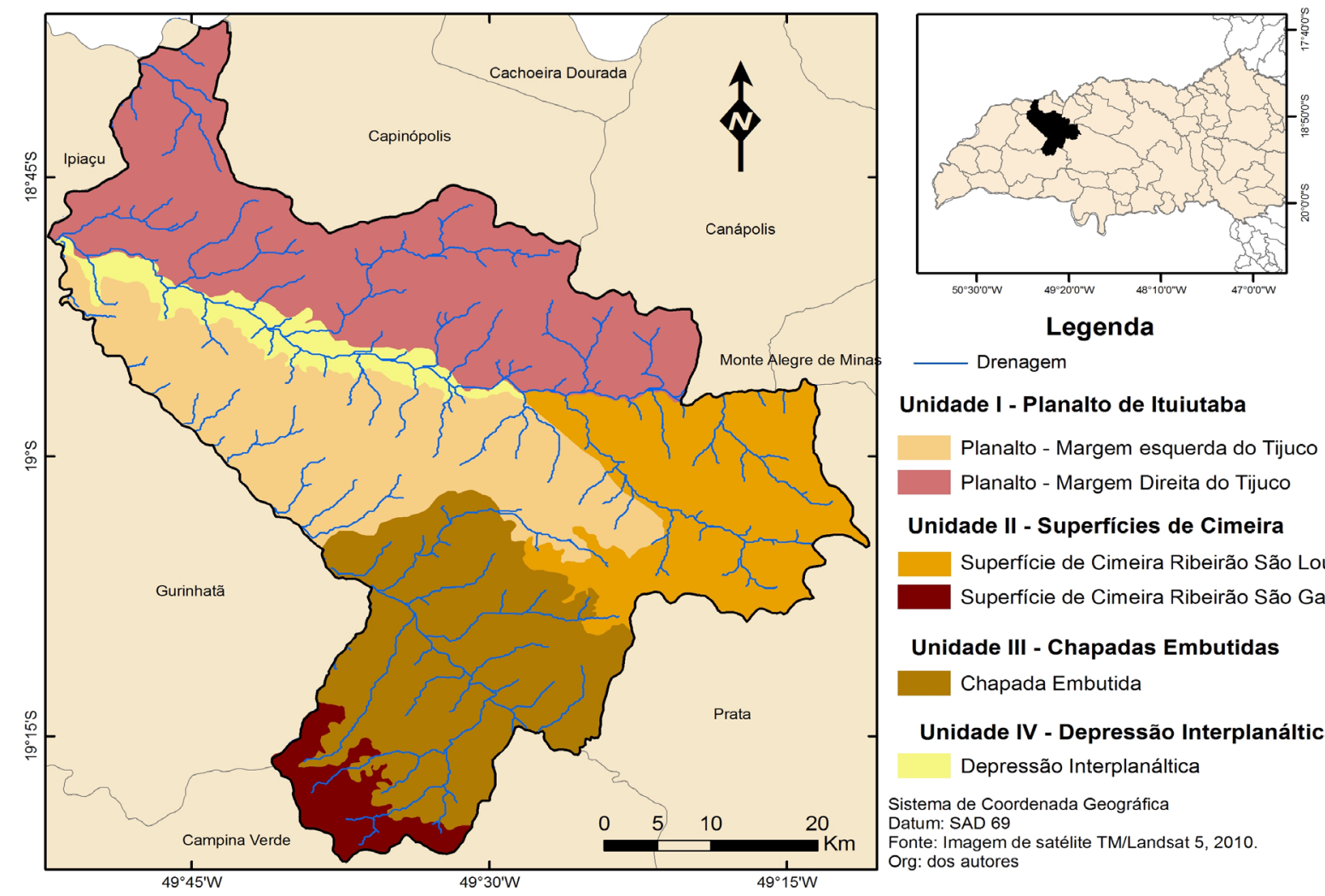

Unidade I - Planalto de Ituiutaba

Planalto - Margem esquerda do Tijuco Planalto - Margem Direita do Tijuco

Unidade II - Superfícies de Cimeira

Superfície de Cimeira Ribeirão São Lourenço Superfície de Cimeira Ribeirão São Gabriel Unidade III - Chapadas Embutidas Chapada Embutida

Unidade IV - Depressão Interplanáltica Depressão Interplanáltica Sistema de Coordenada Geográfica Datum: SAD 69
Fonte: Imagem de satélite TM/Landsat 5, 2010. org: dos autores

Fonte: Imagem de satélite TM/Landsat 5, 2010. Adaptação dos autores. 
A subunidade Planalto margem direita do Tijuco (Ia) localiza-se no sentido E / NW do município de Ituiutaba e possui em sua área os afluentes do rio Tijuco. Já o Planalto da margem esquerda do Tijuco (Ib) está localizado no sentido central do município para NW e possui os afluentes dos rios Tijuco e Prata em sua área. Ambos compreendem o interflúvio dos principais rios do município (Tijuco e Prata). A evolução destas subunidades está relacionada à dissecação do relevo promovida pelos afluentes dessas principais drenagens.
Em decorrência da diferença de resistência dos materiais do substrato rochoso, representados pelos basaltos da Formação Serra Geral (subjacente), e os conglomerados e arenitos do Grupo Bauru, constata-se, ao se aproximar do rio Paranaíba, a presença de áreas com afloramentos de basalto (Figura 5), o qual é o nível de base regional e a montante, nos afluentes Tijuco e Prata, estão expostos os arenitos das formações Adamantina e Marília. Essas duas sub-unidades correspondem à mesma Unidade (Planalto) e possuem dados morfométricos semelhantes (Quadro 2).

Figura 5. Afloramento de basalto nas margens do rio da Prata, Ituiutaba-MG, 2011

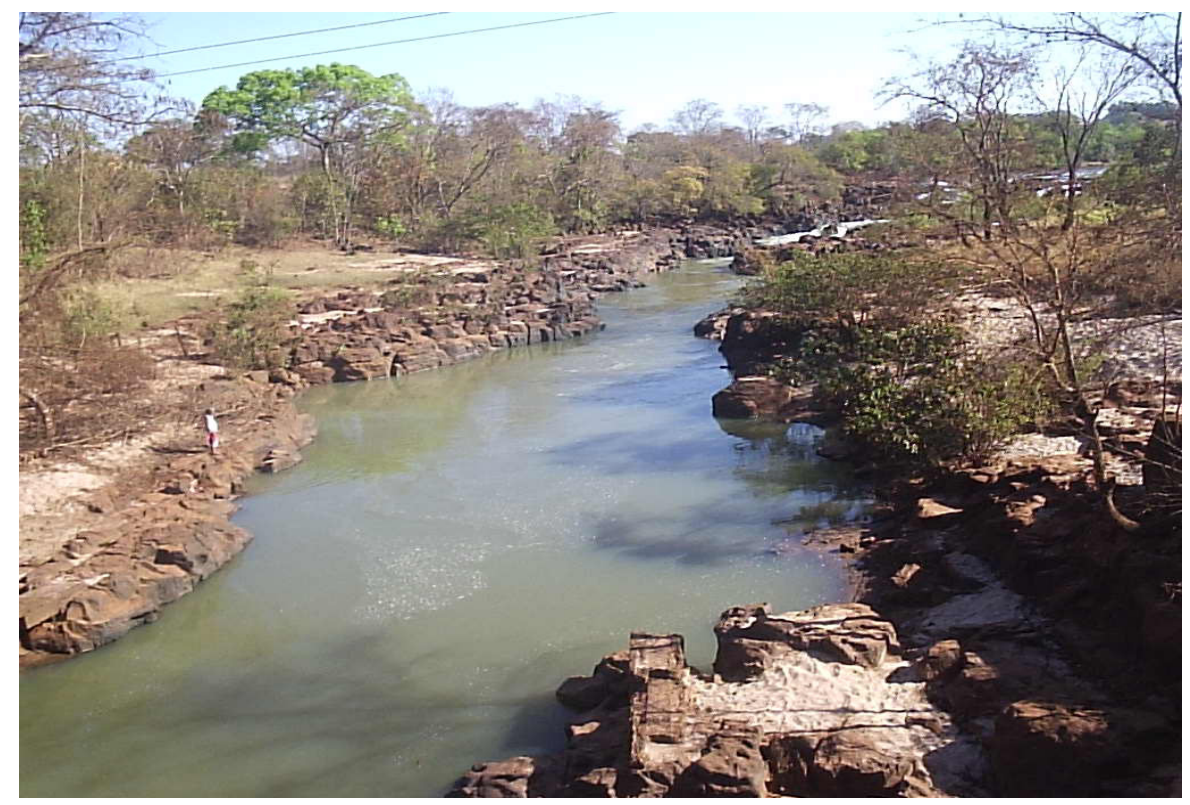

Foto dos autores.

Ambos faziam parte de uma mesma superfície, sendo o rio Tijuco fator primordial na dissecação da paisagem, separando-os. As sub-bacias hidrográficas do Ia são maiores e possuem maior organização e ramificação, capazes de promover elevada dissecação no relevo. Enquanto que o Ib possui bacias de menor porte, devido ao interflúvio existente entre a bacia do rio Tijuco e a bacia do Rio da Prata (Figura3).

Apesar de se assemelharem os valores dos índices morfométricos, a densidade de drenagem possui uma pequena diferença entre estes compartimentos. $\mathrm{O}$ Ib possui maior densidade $\left(1,3 \mathrm{~km}^{2}\right)$ do que o Ia $(0,9$ $\mathrm{km}^{2}$ ), fato este que pode ser atribuído à presença dos afluentes de duas grandes drenagens que margeiam este compartimento, o Rio Tijuco e o Rio da Prata.
Mas, mesmo com esta diferença na densidade de drenagem, os valores para o aprofundamento do Talvegue se mostram idênticos.

Superfícies de Cimeira - A Superfície de Cimeira do Ribeirão São Lourenço (IIa) está localizada a Leste do município de Ituiutaba, enquanto que a Superfície de Cimeira do Ribeirão São Gabriel (IIb) se encontra ao Sul do município.

Os compartimentos IIa e IIb possuem um dos maiores valores de densidade de drenagem, $1,2 \mathrm{~km}^{2} \mathrm{e}$ $1,4 \mathrm{~km}^{2}$ respectivamente, fato este relacionado à alta hipsometria (Figura 1) em relação aos demais compartimentos. Mesmo possuindo um material mais poroso, composto por arenitos do Grupo Bauru, a declividade favorece um maior escoamento superficial. 
Chapada Embutida - Este compartimento possui a segunda maior Dimensão Interfluvial $(2.380 \mathrm{~m})$ no município de Ituiutaba. Comparada com os demais compartimentos, possui baixo valor da declividade dos fundos de vale (4.7\%), fato este que pode, em parte, ser atribuído à baixa densidade hidrográfica $\left(1,1 \mathrm{~km}^{2}\right)$ e à Dimensão Interfluvial.

Depressão Interplanáltica - O Aprofundamen- to do Talvegue é o menor valor encontrado se comparado a todos os compartimentos estudados $(1.030 \mathrm{~m})$ se aproximando do valor adquiridos para os planaltos. Assim como os valores para a Declividade dos Fundos de vale $(5.9 \%)$ são semelhantes ao das subunidades do planalto como era esperado, visto que a dissecação do relevo ocorreu separando os dois compartimentos de Planaltos.

Quadro 2. Compartimentação morfológica e dados morfométricos do município de Ituiutaba.

\begin{tabular}{|c|c|c|c|c|c|c|}
\hline \multicolumn{2}{|c|}{$\begin{array}{l}\text { Unidade Morfológica } \\
\qquad\left(3^{\circ} \text { Taxon }\right)\end{array}$} & \multirow{2}{*}{$\begin{array}{l}\text { Sub-Unidade Morfológica } \\
\text { (Ia)Planalto - Margem } \\
\text { Direita do Tijuco }\end{array}$} & \multirow{2}{*}{$\begin{array}{c}\text { Dimensão } \\
\text { dos } \\
\text { Interflúvios (m) } \\
2.990\end{array}$} & \multirow{2}{*}{$\begin{array}{l}\text { Aprofundamento do } \\
\text { Talvegue (m) } \\
350\end{array}$} & \multirow{2}{*}{$\begin{array}{c}\text { Declividade } \\
\text { dos Fundos de } \\
\text { Vale (\%) } \\
5.9\end{array}$} & \multirow{2}{*}{$\begin{array}{c}\text { Densidade } \\
\text { de Drenagem } \\
\left(\mathrm{Km}^{2}\right) \\
0,9\end{array}$} \\
\hline $\mathrm{I}$ & Planalto de & & & & & \\
\hline 1 & Ituiutaba & $\begin{array}{l}\text { (Ib)Planalto - Margem } \\
\text { Esquerda do Tijuco }\end{array}$ & 2.870 & 350 & 5.1 & 1,3 \\
\hline \multirow{2}{*}{ II } & \multirow{2}{*}{$\begin{array}{l}\text { Superfícies de } \\
\text { Cimeira }\end{array}$} & $\begin{array}{l}\text { (IIa)Superfície de Cimeira } \\
\text { do Ribeirão São Lourenço }\end{array}$ & 2.430 & 390 & 6.9 & 1,2 \\
\hline & & $\begin{array}{l}\text { (IIb)Superfície de Cimeira } \\
\text { do Ribeirão São Gabriel }\end{array}$ & 2.020 & 460 & 5.1 & 1,4 \\
\hline III & $\begin{array}{l}\text { Chapadas } \\
\text { Embutidas }\end{array}$ & $\begin{array}{l}\text { (III)Chapada Embutida do } \\
\text { Alto São Lourenço }\end{array}$ & 2.380 & 430 & 4.7 & 1,1 \\
\hline IV & $\begin{array}{c}\text { Depressão } \\
\text { Interplanáltica }\end{array}$ & $\begin{array}{c}\text { (IV)Depressão Interplanál- } \\
\text { tica do Tijuco }\end{array}$ & 1.030 & 330 & 5.9 & 1,0 \\
\hline
\end{tabular}

Organização dos autores.

Os valores de morfometria auxiliaram tanto na compreensão de como a drenagem está disposta em cada compartimento, quanto na análise das próprias características do relevo, justificando as análises que foram feitas sobre a dinâmica da rede de drenagem e os processos de agradação e degradação. Além disso, verificou-se que esses parâmetros se encontram, muitas vezes, interligados.

\section{AS FORMAÇÕES SUPERFICIAIS COMO COM- PONENTES DE ANÁLISE AMBIENTAL}

Deve-se compreender a estrutura superficial devido à importância das características dos seus depósitos de cobertura, que estão diretamente relacionados ao processo de intemperização e desagregação do solo que causam deslizamento de massas e, principalmente erosões lineares e laminares no município de Ituiutaba.

Os Argissolos aparecem basicamente nas Superfícies de Cimeira e são justificados por serem os locais mais elevados dentro do município, favorecendo a migração de argila dos horizontes superiores para o horizonte B. Enquanto os Latossolos Vermelhos e Nitossolos Vermelhos estão presentes nas áreas mais rebaixadas da paisagem, onde ocorre o afloramento de basalto próximo aos cursos d'água principais.

O Latossolo abrange todos os subcompartimentos da Unidade dos Planaltos, parte da Superfície de Cimeira, Depressão e Chapadas Embutidas. O Gleissolo Melânico está em uma área onde há rede 
de drenagem organizada e conectada, fato este que favorece sua formação.

Essa disposição da cobertura pedológica associada às características do relevo pode ser visualizada a partir das Figuras 2 e 4.

Sendo que especificamente na Figura 6 é possível visualizar a espacialização das classes de solo em cada compartimento morfológico da área de estudo.

Figura 6. Mapa dos Materiais Inconsolidados do Município de Ituiutaba-MG.

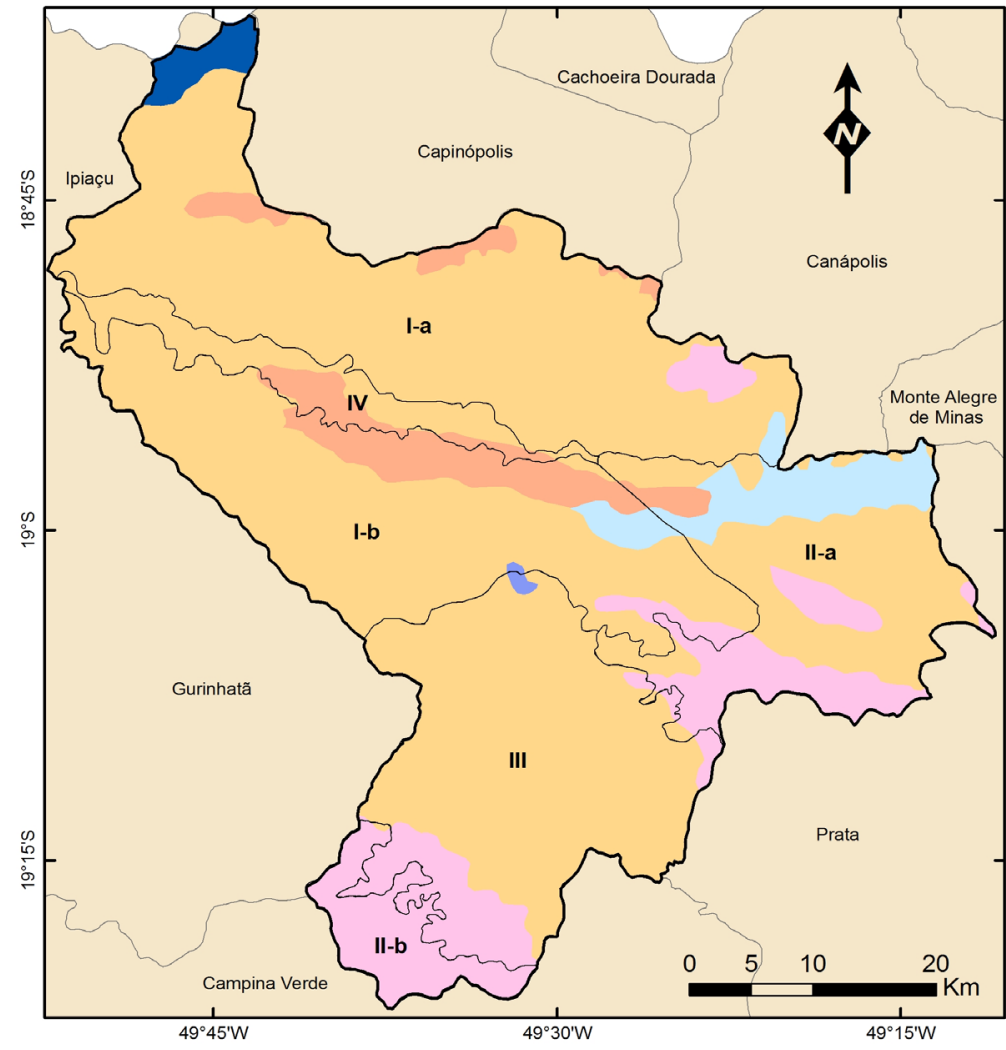

Fonte: Adaptado de Geominas (2011).

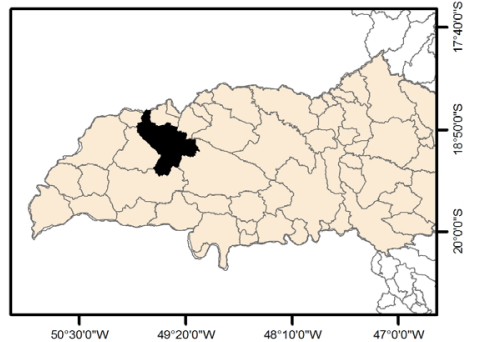

\section{Legenda}

GLEISSOLO MELÂNICO LATOSSOLO VERMELHO NEOSSOLO LITÓLICO ARGISSOLO VERMELHO-AMARELO NITOSSOLO VERMELHO

\section{Divisão de Compartimentos} I-a) Planalto - Margem Direita do Tijuco I-b) Planalto - Margem esquerda do Tijuco II-a) Superfície de Cimeira Ribeirão São Lourenço II-b) Superfície de Cimeira Ribeirão São Gabriel III) Chapada Embutida IV) Depressão Interplanáltica

Drenagem do Rio Paranaíba istema de Coordenada Geográfica. Datum: SAD 69 Fonte: Geominas, 2011. Org: dos autores
O Planalto da Margem Direita do Rio Tijuco (I-a) possui área de 776,02 $\mathrm{km}^{2}$. A estrutura superficial deste compartimento tem quatro classes de solos, sendo $88,34 \%$ referente à classe de Latossolo Vermelho, 4,24\% de Nitossolo Vermelho, 2,7\% de Argissolo Vermelho-Amarelo e $0,81 \%$ de Gleissolo Melânico. E $3,86 \%$ da área total do compartimento estão ocupadas pela drenagem do Rio Paranaíba.

O compartimento Planalto da margem esquerda do Rio Tijuco (I-b), com área de $591,51 \mathrm{~km}^{2}$, é composto por cinco classes de solo. Sendo $80 \%$ da área total do compartimento correspondente à classe de Latossolo Vermelho, 13,8\% de Nitossolo Vermelho, 3\% de Gleissolo Melânico, 2,7\% de Argissolo Vermelho-Amarelo e $0,17 \%$ corresponde a Neossolo Litólico.
O compartimento Superfície de Cimeira do Ribeirão São Lourenço (II-a) possui área de $439,2 \mathrm{~km}^{2}$ e quatro classes de solo distribuídas em: 54,6\% de Latossolo Vermelho, 24\% de Argissolo Vermelho-Amarelo, 18,6\% de Gleissolo Melânico e 2,7\% de Nitossolo Vermelho.

A Superfície de cimeira do Ribeirão São Gabriel (II-b) possui 96,68 km² na qual, com duas classes de solo. Dentre elas há predominância de Latossolo Vermelho, com 99,4\% da área desta subunidade e 0,6\% refere-se a Argissolo Vermelho-Amarelo.

$\mathrm{Na}$ Chapada Embutida (III) foi constatado, em seus $565,32 \mathrm{~km}^{2}$ de área, três classes de solo. No qual o Latossolo Vermelho ocupa 84\% da área, $15,4 \%$ para Argissolo Vermelho-Amarelo e $0,6 \%$ de Neossolos Litólicos. 
A Depressão Interplanáltica (IV) possui área de $119,77 \mathrm{~km}^{2}$, sendo composta em sua estrutura superficial de $94,4 \%$ de Latossolo Vermelho e 5,6\% de Nitossolo Vermelho.

\section{FISIOLOGIA DA PAISAGEM: AAPROPRIAÇÃO DO RELEVO E OS IMPACTOS PROCESSUAIS}

Para análise da Fisiologia da Paisagem (Ab'Sáber, 1969), foi considerado o uso e ocupação da terra no município de Ituiutaba. A partir do tratamento desses dados observou-se a espacialização da interferência do homem no relevo bem como os possíveis reflexos nos processos morfogenéticos.

Da área total do município, 49,89\% é utilizada como pastagem, $25,49 \%$ como vegetação natural, e $23,57 \%$ com práticas agrícolas. O perímetro urbano é correspondente a aproximadamente $1,03 \%$ (Tabela1 e Figura 7).

Tabela 1. Uso da Terra e cobertura vegetal em 2011, Ituiutaba/MG

\begin{tabular}{l|l|l}
\hline Classe & $\begin{array}{l}\text { Área } \\
\mathbf{k m}^{2}\left(^{*}\right)\end{array}$ & $\begin{array}{l}\text { Percentual } \\
(*)\end{array}$ \\
\hline Agricultura & 613.39 & 23,57 \\
Pastagem & 1298.19 & 49,89 \\
Vegetação Natural & 663,46 & 25,49 \\
Perímetro Urbano & 26,92 & 1,03 \\
Corpos d'água & 24,56 & 0,94 \\
\hline
\end{tabular}

*Dados obtidos mediante o mapeamento do uso da terra e cobertura vegetal a partir de imagens de satélite TM/Landsat5.

Figura 7. Uso da Terra e cobertura vegetal em 2011, Município de Ituiutaba/MG

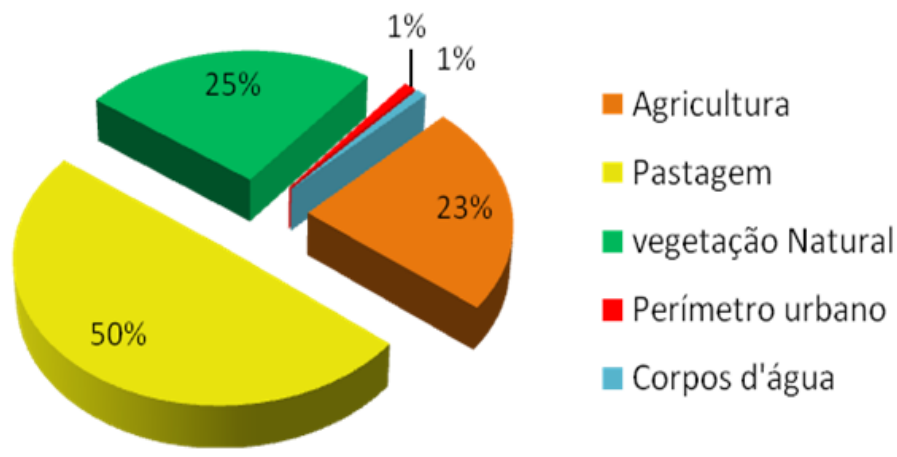

Org. dos autores.

O município de Ituiutaba possui grande parte de sua área utilizada como pastagem (Figura 9a). A qual se encontra cortada por poucas e contínuas áreas de matas ciliares. Além destas, existem áreas de reserva legal, representadas por manchas de cerrado preservadas (Figura 9b).

Enquanto que a agricultura é caracterizada predominantemente pela cultura de cana-de-açúcar (Figura 10), a qual, principalmente a partir do ano de
2007 tem se expandido consideravelmente. Conforme o Canasat (2012) a área cultivada com cana-de-açúcar no período de 2006/07 foi de 8.218 ha, de 2007/08 foi $9.966,2008 / 09$ foi $15.022,2009 / 10$ foi $21.657 \mathrm{e}$ 2010/11 foi 21. 741 ha.

Este fato ocorreu principalmente devido à instalação da usina Bioenergia Ltda no município de Ituiutaba no ano de 2007. Outras culturas também foram consideradas nos dados de agricultura. 
No compartimento Planalto da Margem Direita do Rio Tijuco (Ia) a atividade humana á intensa, com grande aproveitamento agrícola, sobretudo com a monocultura de cana-de-açúcar. O que é facilitado pelo modelado aplainado do relevo (Figura 8).

O Planalto da margem esquerda do Rio Tijuco (I-b) possui extensas áreas ocupadas por monocultura de cana-de-açúcar, entretanto, ainda predomina a categoria de pastagem.

A Superfície de Cimeira do Ribeirão São Lourenço (II-a) é o compartimento que possui grande quantidade de vegetação natural e pastagem. Se comparada com as demais, possui um relevo mais íngreme, caracterizado pela presença de relevos residuais, os quais favorecem o escoamento superficial e, portanto, maior quantidade de canais de drenagem. Não sendo uma área atrativa para o desenvolvimento da agricultura.

Devido a essas características, a preservação da vegetação natural se faz presente. Por conter vários canais de primeira ordem, há exigência em se cumprir a legislação que versa sobre a preservação de Áreas de Preservação Permanente (APPs), a qual inclui as matas ciliares.

Figura 8. Carta do Uso do Solo do Município de Ituiutaba-MG.
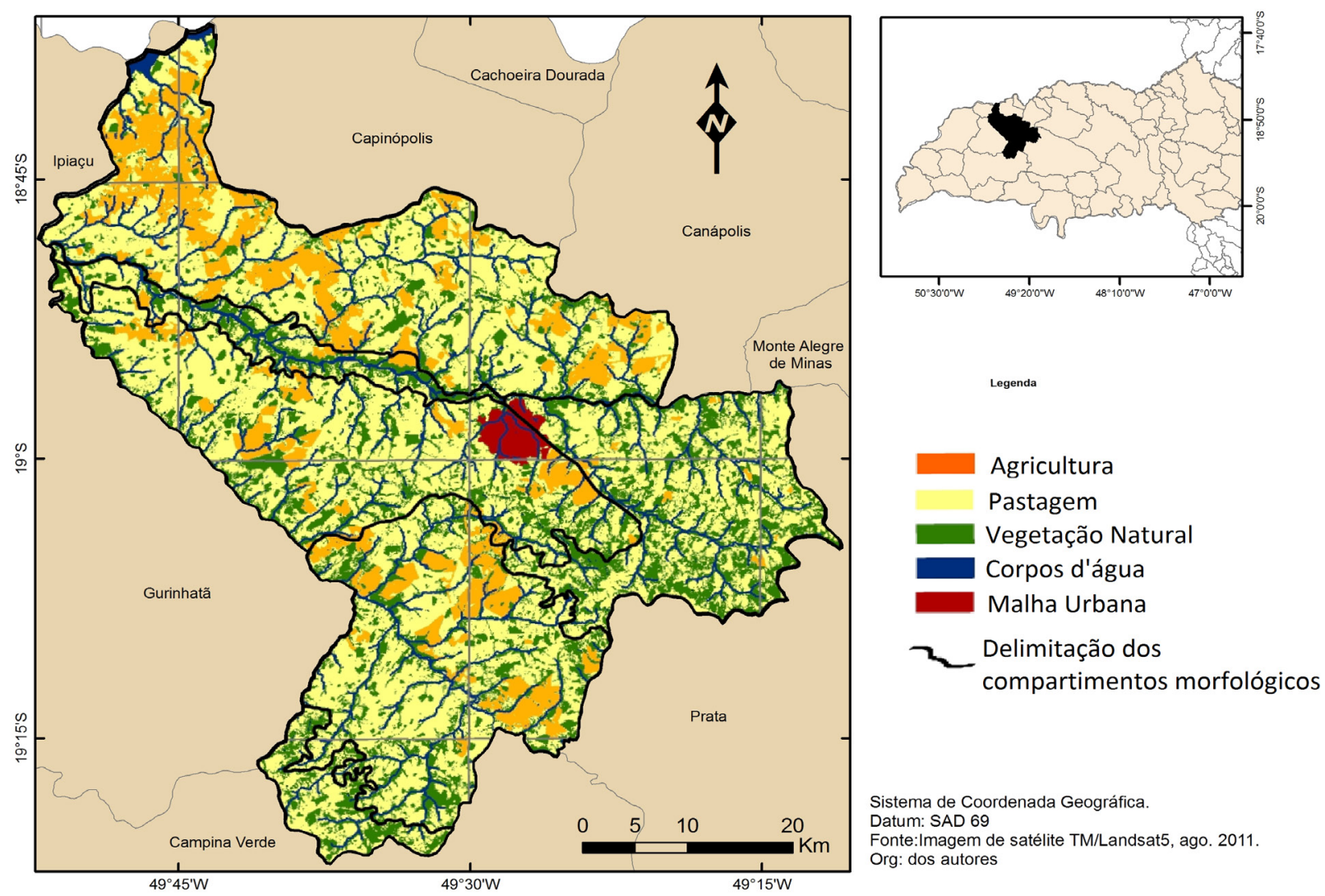

Fonte: Imagem de satélite TM/Landsat5, 2011. Org. dos autores. 
Figura 9. Município de Ituiutaba-MG,: (a) Pastagem, (b) Estrada circundada com Área de Preservação Permanente.

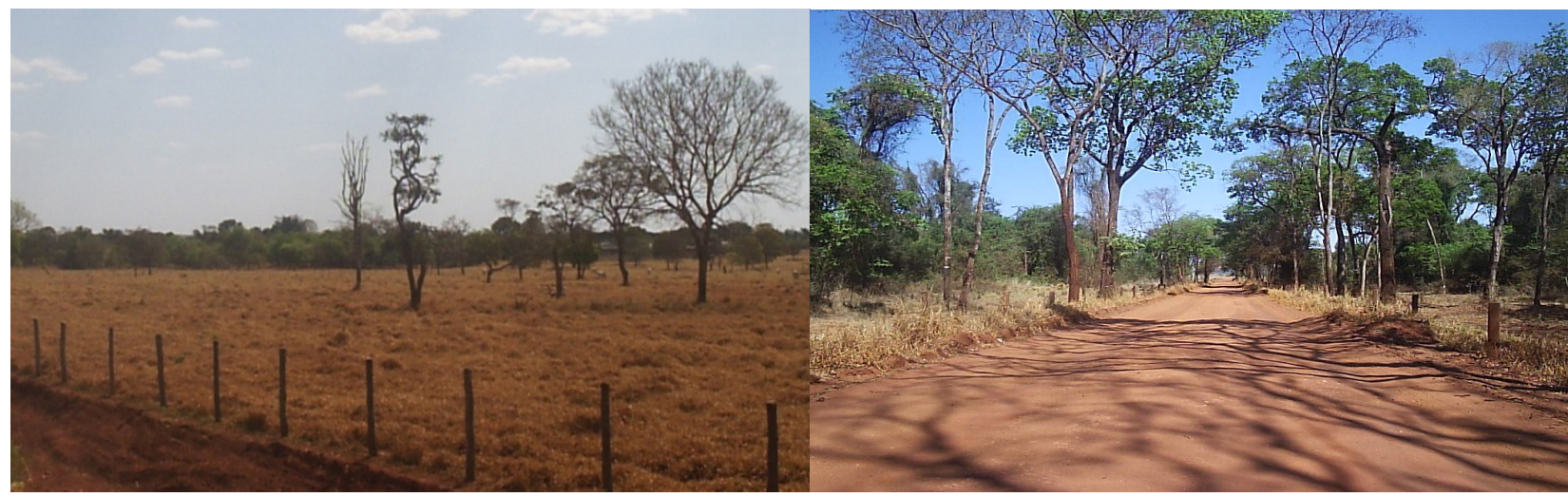

Foto dos autores (agosto de 2011).

Figura 10. Município de Ituiutaba-MG. a) Área de plantio de Cana-de-açúcar; b) área com palhas de cana-deaçúcar após colheita mecanizada.

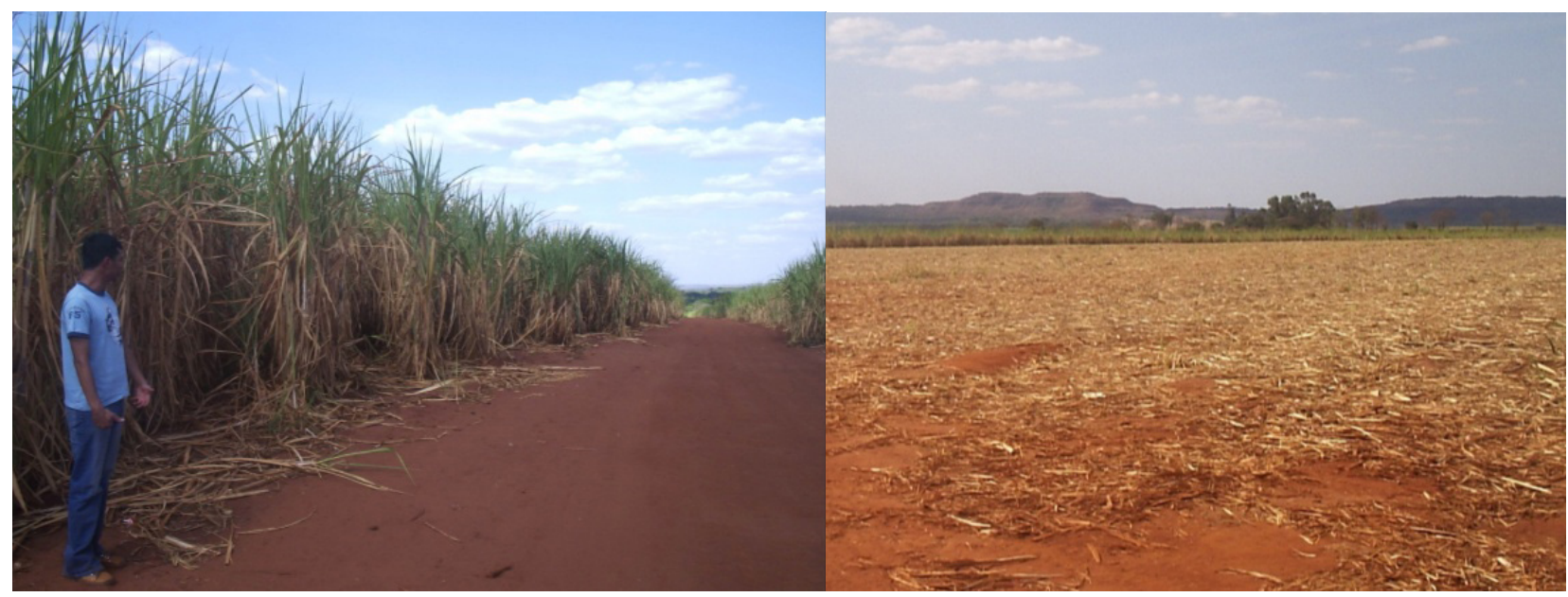

Foto dos autores (agosto de 2011).

A Superfície de cimeira do ribeirão São Gabriel (II-b) possui características semelhantes à compartimentação acima descrita. Entretanto, há predominância da categoria Pastagem.

$\mathrm{Na}$ Chapada Embutida (III) apesar de existir extensa área de monocultura de cana-de-açúcar, a Pastagem ainda é a categoria mais representativa.

A Depressão Interplanáltica (IV) compreende as margens do rio Tijuco, com predominância da categoria de vegetação natural. Ao comparar o estudo de Rezende e Rosendo (2009) com os dados deste trabalho, nota-se que, em todo o município, a área com vegetação natural não teve consideráveis modificações entre o ano de 2007 e 2011. As áreas que ainda possuem esta categoria se mostram como o cumprimento da legislação vigente do Código Florestal Brasileiro (Lei 4.771, de 15 de setembro de 1965). O qual define as normas de uso, preservação e conservação das florestas e outros tipos vegetativos utilizando parâmetros básicos: as Áreas de Preservação Permanente (APP) e Reserva Legal (ARL).

\section{CONSIDERAÇÕES FINAIS}

A compartimentação do município de Ituiutaba foi estabelecida a partir da interpretação do relevo quanto à dissecação devido à ação da rede drenagem. 
Entretanto, essas unidades e subunidades estabelecidas para o município não possuem extrema diferenciação nos valores dos parâmetros amostrados. Assim, apesar de existirem algumas diferenças ao se comparar os dados morfométricos de cada subunidade, ressalta-se que a área do município de Ituiutaba é homogênea do ponto de vista geomorfológico.

Os locais com maiores altitudes estão em processo de dissecação e são áreas que contêm feições geomorfológicas do tipo relevo residuais. Em contraposição, os locais mais rebaixados e retilíneos foram muito dissecados pela drenagem e atualmente são áreas em que afloram os basaltos da Formação Serra Geral.

Quanto às formações superficiais, os Latossolos Vermelhos representam a classe predominante dentro do limite municipal e está presente em todos os compartimentos, exceto na Superfície de Cimeira Ribeirão São Gabriel.

No que se refere ao uso e ocupação da terra, nota-se que a cana-de-açúcar é a cultura predominante e que tem adquirido áreas cada vez maiores para seu plantio. Entretanto, a aquisição de novas áreas refere-se, principalmente, àquelas anteriormente utilizadas como pastagem, a qual ainda é a categoria de uso da terra predominante no município.

A compartimentação do relevo do município de Ituiutaba com base na ação da rede de drenagem sobre a esculturação do relevo mostra a dinâmica pretérita de desenvolvimento da paisagem e como esta tem evoluído atualmente, sendo base para separar compartimentos que apresentam semelhanças e, portanto, são passíveis de utilização como uma unidade de planejamento. Os dados morfométricos, pedológicos e de uso e ocupação da terra fornecem uma caracterização ambiental integrada, na qual o ambiente físico e a dinâmica da ocupação do relevo pelo homem são bases imprescindíveis a um planejamento otimizado.

Os dados em análise forneceram uma caracterização física do município de Ituiutaba e podem inferir discussões sociais à medida que integra a dinâmica de apropriação do relevo. A junção destes parâmetros constitui base para uma análise ambiental integrada a qual poderá ser útil para se avançar nos estudos do município de Ituiutaba, principalmente aqueles direcionados à vulnerabilidade ambiental.

\section{REFERÊNCIAS}

AB'SÁBER, A. N. Um conceito de geomorfologia a serviço de pesquisas sobre o quaternário. Geomorfologia. São Paulo, v. 18, p.01-20, 1969.

BACCARO, C. A. D. Unidades geomorfológicas do Triângulo Mineiro - Estudo Preliminar. Sociedade e Natureza. Uberlândia, v. 3, n. 5/6, p.37-42, 1991.

BARBOSA, O. Geologia da região do Triângulo Mineiro. Rio de Janeiro: Ministério das Minas e Energia, DNPM, 1970.

BATEZELli, A. Análise da Sedimentação Cretácea no Triângulo Mineiro e sua Correlação com Áreas Adjacentes. 183 f. Tese (Doutorado em Geologia), Instituto de Geociências e Ciências Exatas, UNESP, Rio Claro, 2003.

CANASAT/INPE. Canasat (Dados de área cultivada com cana-de-açúcar). Disponível em: <http://www. dsr.inpe.br/laf/canasat/tabelas.html $>$. Acesso em: 10 jan. 2012.

CASSETI, V. Proposta metodológica para elaboração de carta de risco. Boletim Goiano de Geografia. Goiânia, v.15, n.1, p. 81-88, 1995.

BRASIL. Lei $n$. 4.771, de 15 de setembro de 1965. Institui o novo Código Florestal. Disponível em: $<$ http://www2.camara.leg.br/legin/fed/lei/1960-1969/ lei-4771-15-setembro-1965-369026-norma-pl.html>. Acesso em: 17 set. 2011.

COSTA, R. A.; MARTINS, F. P. Impactos e Riscos Ambientais Urbanos em Ituiutaba-MG. In: PORTUGUEZ, A. P.; MOURA, G. G.; COSTA, R. A. (Org). Geografia do Brasil Central: enfoques teóricos e particularidades regionais. Uberlândia: Assis Editora, 2011. p. 355-378.

CREPANI, E. et al. Sensoriamento remoto e geoprocessamento aplicados ao zoneamento Ecológico-Econômico. São José dos Campos: INPE, 1998. 
DEL GROSSI, S. R. De Uberabinha a Uberlândia. Os caminhos da natureza - Contribuição ao Estudo da Geomorfologia Urbana. Tese (Doutorado em Geografia), Faculdade de Filosofia, Letras e Ciências Humanas, USP, São Paulo, 1991.

EMBRAPA. Centro Nacional e Pesquisa em Solos. Sistema Brasileiro de classificação de Solos. Rio de Janeiro: Embrapa Solos, 2006.

FERNANDES, L. A.; COIMBRA, A. M. Estratigrafía y ambientes deposicionales de La Cuenca Bauru (Cretácico superior, Brasil). Acta Geologica Hispanica, v. 30, n 4, p.11-30, 1996.

GUERRA, A. T.; GUERRA. A. J. T. Dicionário Geológico-Geomorfológico. Rio de Janeiro: Bertrand Brasil, 1997.

MARTINS, F. P.; ROCHA. L. C. O papel da incisão da rede de drenagem na dissecção dos relevos residuais do "Pontal do Triângulo Mineiro". In: SIMPÓSIO BRASILEIRO DE GEOGRAFIA FÍSICA APLICADA, XIV, 2011, Dourados/MS. Anais... Dourados: UFGD, 2011.

MINAS GERAIS. Bases Cartográficas. Disponível em: <http://geominasgeo.com.br/site/>. Acesso em: 09 jan. 2011.

BRASIL (Ministério do Meio Ambiente). Mapa de Cobertura Vegetal dos Biomas Brasileiros. Disponível em: <http://mapas.mma.gov.br/mapas/aplic/probio/ datadownload.htm?/>. Acesso em: 07 mai. 2011.

NISHIYAMA, L. Geologia do município de Uberlândia e áreas adjacentes. Sociedade \& Natureza. Uberlândia, v. 1, n. 1, p. 9-15, 1989.
PRADO, V. G. T. J.; SOUSA, R. R. Mapa Pluviométrico do Triângulo Mineiro. (Relatório Final de Iniciação Científica). Ituiutaba: UFU/FACIP, 2010.

REZENDE, M; ROSENDO, J. R. Análise da evolução da ocupação do uso da terra no município de Ituiutaba-MG utilizando técnicas de geoprocessamento e sensoriamento remoto. Rev. Horizonte Cientifico, Uberlândia, v. 3, n. 1, s/p, 2009.

ROSA. R. Metodologia de Interpretação visual de dados. In: Introdução ao sensoriamento remoto. Uberlândia: EDUFU, 2007. p. 157-186.

ROSS, J. A. S. Geomorfologia: ambiente e planejamento. São Paulo: Contexto, 1991.

ROSS, J. A. S. O registro cartográfico e a questão da taxonomia do relevo. Revista de Geografia, São Paulo, v. 6, p.1-20, 1992.

RUDORFF, B. F. T.; AGUIAR, D. A de.; SILVA, W. F da.; SUGAWARA, L. M.; ADAMI, M. MOREIRA, M. A. Studies on the Rapid Expansion of Sugarcane for Ethanol Production in São Paulo State (Brazil) Using Landsat Data. Remote Sensing. Ottawa, v. 2, n. 4, p. 1057-1076, 2010. DOI: http://dx.doi.org/10.3390/ rs2041057

SILVA, L. R. G.; ROCHA, L. C.; MARTINS, F. P.; SILVA, G. A. Espacialização e Caracterização dos Relevos Residuais do Município de Ituiutaba/Minas Gerais. In: VIII SIMPÓSIO NACIONAL DE GEOMORFOLOGIA, Recife, 2010. Anais... Recife: AGB/ UFPE, 2010. 